Correspondence

Robert R. Brubaker

t-rbruba@bsd.uchicago.edu

Received 10 June 2008

Revised 29 September 2008

Accepted 1 October 2008

\title{
Attenuated enzootic (pestoides) isolates of Yersinia pestis express active aspartase
}

\author{
Scott W. Bearden, ${ }^{1}$ Christopher Sexton, ${ }^{1}$ Joshua Pare, ${ }^{2}$ Janet M. Fowler, ${ }^{2}$ \\ Cindy G. Arvidson, ${ }^{2}$ Lyudmyla Yerman, ${ }^{3}$ Ronald E. Viola ${ }^{3}$ \\ and Robert R. Brubaker ${ }^{4}$
}

\author{
${ }^{1}$ Centers for Disease Control and Prevention, Division of Vector-Borne Infectious Diseases, \\ Bacterial Diseases Branch, Fort Collins, CO 80521, USA \\ ${ }^{2}$ Department of Microbiology and Molecular Genetics, Michigan State University, 2215 Biomedical \\ Physical Sciences, East Lansing, MI 48824, USA \\ ${ }^{3}$ Department of Chemistry, University of Toledo, 2801 W. Bancroft Street, Toledo, OH 43606, USA \\ ${ }^{4}$ Department of Microbiology, The University of Chicago, 920 E. 58th Street, Chicago, IL 60637, \\ USA
}

\begin{abstract}
It is established that Yersinia pestis, the causative agent of bubonic plague, recently evolved from enteropathogenic Yersinia pseudotuberculosis by undergoing chromosomal degeneration while acquiring two unique plasmids that facilitate tissue invasion (pPCP) and dissemination by fleabite (pMT). Thereafter, plague bacilli spread from central Asia to sylvatic foci throughout the world. These epidemic isolates exhibit a broad host range including man as opposed to enzootic (pestoides) variants that remain in ancient reservoirs where infection is limited to muroid rodents. Cells of $Y$. pseudotuberculosis are known to express glucose-6-phosphate dehydrogenase (Zwf) and aspartase (AspA); these activities are not detectable in epidemic $Y$. pestis due to missense mutations (substitution of proline for serine at amino position 155 of Zwf and leucine for valine at position 363 of AspA). In this study, functional Zwf was found in pestoides strains E, F and G but not seven other enzootic isolates; enzymic activity was associated with retention of serine at amino acid position 155. Essentially, full AspA activity occurred in pestoides isolates where valine (pestoides A, B, C and D) or serine (pestoides E, F, G and I) occupied position 363. Reduced activity occurred in strains Angola and A16, which contained phenylalanine at this position. The $k_{\text {cat }}$ but not $K_{\mathrm{m}}$ of purified AspA from strain Angola was significantly reduced. In this context, aspA of the recently described attenuated enzootic microtus biovar encodes active valine at position 363 , further indicating that functional AspA is a biomarker for avirulence of $Y$. pestis in man.
\end{abstract}

\section{INTRODUCTION}

Yersinia pseudotuberculosis diverged from Yersinia enterocolitica about one million years ago (Achtman et al., 1999). During subsequent evolution, the organism acquired a tropism for lymphatic tissue and gained unique LPS Ogroups (Davies, 1961) and new enzymes including KatY (Garcia et al., 1999). Nevertheless, Y. pseudotuberculosis remains an enteropathogenic species although its incidence of soil-borne zoonotic infection is generally greater than that of $Y$. enterocolitica, which typically causes food-borne gastrointestinal disease in humans. Both of these patterns are in stark contrast to the epidemic habit of Yersinia pestis. Probably less than 20000 years have elapsed since Y. pestis

Abbreviations: Caf1, capsular antigen fraction 1; CRIM, cross-reacting immunological material; LCR, low calcium response; MT, murine toxin; Pla, plasminogen activator; T3SS, type III secretion system. diverged from Y. pseudotuberculosis (Achtman et al., 1999), yet plague bacilli cause the most devastating acute infectious disease known to man as judged by its rapid onset, systemic pathology and extensive mortality. The brief existence of $Y$. pestis as a distinct species suggests that only a limited number of genetic changes have occurred that promote acute disease. This possibility was supported by comparative annotation of the $Y$. pestis and $Y$. pseudotuberculosis genomes (Chain et al., 2004, 2006; Deng et al., 2002; Parkhill et al., 2001). Results of these studies detected only a few $Y$. pestis-specific genes whereas about $13 \%$ of the $Y$. pseudotuberculosis chromosome is now inactive in $Y$. pestis (Chain et al., 2004). These losses accrued as a consequence of chromosomal duplication, deletion, inversion, transposition, and the insertion of over 70 copies of IS elements (Chain et al., 2004, 2006; Deng et al., 2002; Parkhill et al., 2001). In addition, cells of typical 
$Y$. pestis as compared to $Y$. pseudotuberculosis possess an assumed missense mutation in glucose-6-phosphate dehydrogenase characterized by a single base transversion $(\mathrm{T} \cdot \mathrm{A} \rightarrow \mathrm{C} \cdot \mathrm{G})$, causing replacement of active serine by proline at amino acid position 155 (Chain et al., 2004), and a proven missense mutation (Viola et al., 2008) in aspartate ammonia-lyase or aspartase (AspA) characterized by a single base transversion $(\mathrm{G} \cdot \mathrm{C} \rightarrow \mathrm{T} \cdot \mathrm{A})$, causing replacement of active valine by leucine (Chain et al., 2004). The existence of these various types of loss mutation accounts for most of the classic phenotypic differences used to distinguish $Y$. pestis from $Y$. pseudotuberculosis (Brubaker, 1991).

The few important $Y$. pestis-specific genes were acquired by lateral transfer as evidenced by carriage of two plasmids not shared with the enteropathogenic yersiniae (Ferber \& Brubaker, 1981). These consist of $\sim 10 \mathrm{~kb}$ pPCP encoding plasminogen activator ( $\mathrm{Pla}$ ), the bacteriocin pesticin, and its immunity protein (Ferber \& Brubaker, 1981), and $\sim 100 \mathrm{~kb}$ pMT encoding capsular antigen fraction 1 (Caf1) and murine toxin (MT) (Kutyrev et al., 1986; Protsenko et al., 1983). Plague bacilli share a third $\sim 70 \mathrm{~kb}$ plasmid with the enteropathogenic yersiniae (termed $\mathrm{pCD}$ in $Y$. pestis and $\mathrm{pYV}$ in Y. pseudotuberculosis and Y. enterocolitica). The latter mediates a low calcium response (LCR) causing a temperature-dependent nutritional requirement in vitro for $\sim 2.5 \mathrm{mM} \mathrm{Ca}^{2+}$ (Kupferberg \& Higuchi, 1958). If present, $\mathrm{Ca}^{2+}$ promotes vegetative growth at $37{ }^{\circ} \mathrm{C}$ while downregulating a host temperature-dependent $\mathrm{pCD} / \mathrm{pYV}$ encoded type III secretion system (T3SS) required for translocation of attendant virulence effectors. These determinants consist of yersiniae outer proteins (Yops) and LcrV, which collectively disrupt host cell scaffolding, cause apoptosis and repress inflammation (Heesemann et al., 2006). If $\mathrm{Ca}^{2+}$ is omitted from the environment in vitro, the organisms upregulate this T3SS and cease multiplication $\left(\mathrm{Lcr}^{+}\right)$, although full-scale growth can still occur at mildly acidic $\mathrm{pH}$ provided that $\mathrm{Na}^{+}$is also eliminated from the medium (Brubaker, 2007). The LCR is particularly stringent in $\mathrm{Lcr}^{+}$cells of $Y$. pestis as judged by abrupt shutoff of growth following shift from $26{ }^{\circ} \mathrm{C}$ to $37^{\circ} \mathrm{C}$ associated with secretion of L-aspartic acid (Brubaker, 2005, 2007). This phenomenon reflects loss of AspA activity (Dreyfus \& Brubaker, 1978), where exit of metabolic L-aspartate likely contributes to the abrupt shutoff in growth of $\mathrm{Lcr}^{+}$cells of $Y$. pestis. Since bacteriostasis as well as release of L-aspartate in $\mathrm{Ca}^{2+}$ deficient medium is dependent on the presence of $\mathrm{Na}^{+}$ (Brubaker, 2005, 2007; Fowler \& Brubaker, 1994), the possibility exists that the latter cation causes both phenomena via its established role as porter for the translocation of L-aspartate via GltS (Deguchi et al., 1990). As noted below, the possibility also exists that missing Zwf activity (Mortlock, 1962; Mortlock \& Brubaker, 1962) may also influence the LCR of $Y$. pestis during growth in vitro.

Cells of $Y$. pseudotuberculosis actively invade host intestinal epithelial cells and typically downregulate the formation of a biofilm required by $Y$. pestis for blockage of fleas. Both of these properties have been lost by mutation in $Y$. pestis (Brubaker, 2004; Sun et al., 2008). It is also established that acquisition of MT via pMT facilitated colonization of the flea vector (Hinnebusch et al., 2002), thereby enabling the organisms to bypass natural environments by undergoing direct passage from one host to another. Little is known, however, about the sequence of these and other genetic changes that culminated in the ability of $Y$. pestis to express acute disease. For successful reliance upon transfer by fleabite, the organisms must kill their current rodent host in order to ensure that resident fleas disseminate in search of new hosts. Accordingly, mortality became an essential part of the life cycle of $Y$. pestis and selective pressure caused by the necessity for lethality has undoubtedly favoured subsequent increases in virulence. As a consequence, plague bacilli became efficient pathogens and have recently disseminated from ancient foci in central Asia to reservoirs throughout the world, where they now cause acute disease in a large number of animal species including man (Suntsov \& Suntsova, 2008). The virulence of these potential 'epidemic' isolates contrasts sharply with 'enzootic' strains (including pestoides variants) of $Y$. pestis that remain contained within the original reservoirs where the species evolved (Anisimov et al., 2004; Martinevskii, 1969). Enzootic isolates are now classified according to subspecies designation (altaica, caucasica, hissarica, ulegeica and talassica; Anisimov et al., 2004) and commonly retain the normal ability of $Y$. pseudotuberculosis to ferment the sugars rhamnose and melibiose. They may also possess all known virulence factors of epidemic isolates. Nevertheless, enzootic strains are attenuated in many mammalian species, including guinea pigs and primates, but virulent in the rodent Superfamily Muroidea (Anisimov et al., 2004). Although pestoides isolates possess polymorphism in LcrV (Anisimov et al., 2007), a major $\mathrm{pCD} / \mathrm{pYV}$ encoded regulator, T3SS effector, and virulence factor, it seems unlikely that these differences influence biological activity (Abramov et al., 2007). The purposes of this report are to provide a description of ten typical enzootic isolates and to demonstrate that only three produce functional Zwf while, in stark contrast to epidemic isolates of $Y$. pestis, all express biologically active AspA.

\section{METHODS}

Bacteria and cultivation. Bacterial strains were obtained from stock culture collections of the Centers for Disease Control and Prevention, Fort Collins, CO, or Michigan State University. Both epidemic and enzootic strains of $Y$. pestis were initially screened for the deletable Pgm locus by ability to form pigmented colonies at $26{ }^{\circ} \mathrm{C}$ on Congo red agar (Surgalla \& Beesley, 1969). Plasmid profiles were characterized by electrophoresis in agarose (Kado \& Liu, 1981). If plasmids or the Pgm locus were detected in original stock cultures, routine cultural precautions were undertaken to enrich their content in populations used for later experiments. Avirulent $\mathrm{Lcr}^{-}$derivatives (lacking $\mathrm{pCD} / \mathrm{pYV}$ ) were selected by plating and incubation on magnesium oxalate agar at $37{ }^{\circ} \mathrm{C}$ (Higuchi \& Smith, 1961) to facilitate subsequent biochemical testing and enzymic analyses, 
although isolates containing $\mathrm{pCD}$, if present, were used whenever possible to determine plasmid profiles (Fig. 1). Assurance that missing plasmids had not undergone integration into the chromosome was obtained by query of salient genes (pla, cafl and $l \mathrm{crV}$ ) via PCR; retention of the temperature-dependent nutritional requirement for $\mathrm{Ca}^{2+}$ by strains containing pCD was verified by use of magnesium oxalate agar. Yersiniae grown to late-exponential phase at $37{ }^{\circ} \mathrm{C}$ in brain heart infusion broth (Beckton Dickinson) were used to express Cafl and MT, which were determined by diffusion against monospecific polyclonal antisera in gels and by immunoblotting. Most of the pestoides strains used in this study were also described by Achtman et al. (2004).

Determinative assays. Ability of near-homogeneous populations of $\mathrm{Pgm}^{+}$cells to generate $\mathrm{Pgm}^{-}$mutants at high frequency (Brubaker, 1969) was estimated after incubation for 2 days at $26{ }^{\circ} \mathrm{C}$ on Congo red agar (Surgalla \& Beesley, 1969). Pesticin was purified to nearhomogeneity by the method of Hu \& Brubaker (1974) and assayed at $37{ }^{\circ} \mathrm{C}$ for antibacterial activity on pesticin agar against the indicator organism under investigation (Brubaker \& Surgalla, 1962). Sensitivity to pesticin was expressed in units, where one unit is defined as the reciprocal of the highest dilution providing detectable inhibition of growth. Production of pesticin was estimated qualitatively as ability of colonies to form zones of inhibition in overlayers of pesticin agar after seeding with cells of $Y$. pseudotuberculosis and incubation for 1 day at $37{ }^{\circ} \mathrm{C}$ (Brubaker \& Surgalla, 1962). Pla was determined semiquantitatively by testing dilutions of bacteria washed in $0.033 \mathrm{M}$ potassium phosphate buffer, pH 7.0, on fibrin plates (Astrup \& Mullertz, 1952) as described previously (Beesley et al., 1967). Units of Pla were defined as the reciprocal of the highest dilution yielding fibrinolytic activity. These results and the original geographical origins of individual yersiniae are listed in Table 1 .

All biochemical assays, including expression of motility in $0.5 \%$ Tryptose phosphate agar (Beckton Dickinson), were undertaken at $26{ }^{\circ} \mathrm{C}$. Abilities to reduce nitrate and hydrolyse urea were determined in urea and nitrate broth (Beckton Dickinson), respectively, and fermentation of carbohydrates was assayed in Purple broth (Beckton Dickinson) containing $1 \%(\mathrm{w} / \mathrm{v})$ glycerol, L-rhamnose or melibiose (Sigma). Nutritional requirements were initially screened on solid minimal medium (Brubaker \& Sulen, 1971) containing L-threonine, L-methionine, L-phenylalanine, L-isoleucine and L-valine and modified by omission of glycine and D-lactate; this medium is sufficient for growth of typical epidemic isolates of $Y$. pestis at $26{ }^{\circ} \mathrm{C}$.
Cell-free extracts. Unless stated otherwise, bacteria used for preparation of cell-free extracts for enzyme analysis were always grown at $26{ }^{\circ} \mathrm{C}$. The organisms were transferred from buffered glycerol stock cultures maintained at $-20{ }^{\circ} \mathrm{C}$ (Beesley et al., 1967) to slopes of blood agar base (Becton Dickinson). After incubation for $48 \mathrm{~h}$, the organisms were removed from the agar surface in sterile $0.033 \mathrm{M}$ potassium phosphate buffer $(\mathrm{pH} 7.0)$ and inoculated at an optical density $(620 \mathrm{~nm}$ ) of 0.1 into $100 \mathrm{ml}$ brain heart infusion broth (Beckton Dickinson) contained in a stoppered 11 Erlenmeyer flask. This subculture was aerated overnight at 200 r.p.m. on a model G76 gyrotary water bath shaker (New Brunswick Scientific) and then used to inoculate second cultures of the same medium $(200 \mathrm{ml}$ per 21 Erlenmeyer flasks), which were similarly aerated until the cultures entered the late-exponential growth phase. The bacteria were then harvested by centrifugation (10000 $\mathrm{g}$ for $30 \mathrm{~min}$ ), washed twice in $0.033 \mathrm{M}$ potassium phosphate buffer $(\mathrm{pH} 7.0)$, suspended in $0.05 \mathrm{M}$ Tris/HCl buffer ( $\mathrm{pH} 8.0$ ), and disrupted by passage through a French pressure cell (model FA030, Spectronic Unicam). Cell debris was then removed by centrifugation $(10000 \mathrm{~g}$ for $30 \mathrm{~min})$ and the resulting extracts were dialysed overnight at $4{ }^{\circ} \mathrm{C}$ against $0.05 \mathrm{M}$ Tris $/ \mathrm{HCl}$ buffer ( $\mathrm{pH}$ 7.5) before immediate use in enzyme assays.

Enzyme assays. Zwf was determined by monitoring glucose-6phosphate-dependent generation of NADPH by a minor modification of the assay described previously (Mortlock \& Brubaker, 1962). The reaction mixture consisted of $100 \mu \mathrm{mol}$ Tris/ $\mathrm{HCl}(\mathrm{pH} 8.0), 2.0 \mu \mathrm{mol}$ $\mathrm{MgCl}_{2}, \quad 0.3 \mu \mathrm{mol} \mathrm{NADP}{ }^{+}$and $100 \mu \mathrm{mol}$ glucose 6-phosphate (Sigma) in a volume of $2.9 \mathrm{ml}$ contained within a quartz cuvette. The reaction was started by addition of $0.1 \mathrm{ml}$ dialysed cell-free extract and increase of absorbance at $340 \mathrm{~nm}$ was monitored with a Beckman DU spectrophotometer (Beckman Coulter).

AspA was estimated by determining the L-aspartic acid-dependent release of $\mathrm{NH}_{4}^{+}$with Nessler's reagent as described previously (Dreyfus \& Brubaker, 1978). The reaction mixture consisted of $250 \mu \mathrm{mol}$ Tris/ $\mathrm{HCl}$ (pH 7.0), $5.0 \mu \mathrm{mol} \mathrm{MgCl}_{2}$ and dialysed cell-free extract in a total volume of $4.5 \mathrm{ml}$. The assay was started by addition of $250 \mu \mathrm{mol}$ sodium L-aspartate in a volume of $0.5 \mathrm{ml}$ and samples of $0.5 \mathrm{ml}$ were removed at intervals and added to Eppendorf tubes containing $0.1 \mathrm{ml} 1.5 \mathrm{M}$ trichloroacetic acid. The tubes were then centrifuged at highest speed for $1 \mathrm{~min}$ in a model II microfuge (Beckman Coulter) and then $0.5 \mathrm{ml}$ of clear supernatant fluid was carefully removed and added to a tube containing $8.5 \mathrm{ml}$ distilled water. These samples received $1.0 \mathrm{ml}$ Nessler's reagent and, after

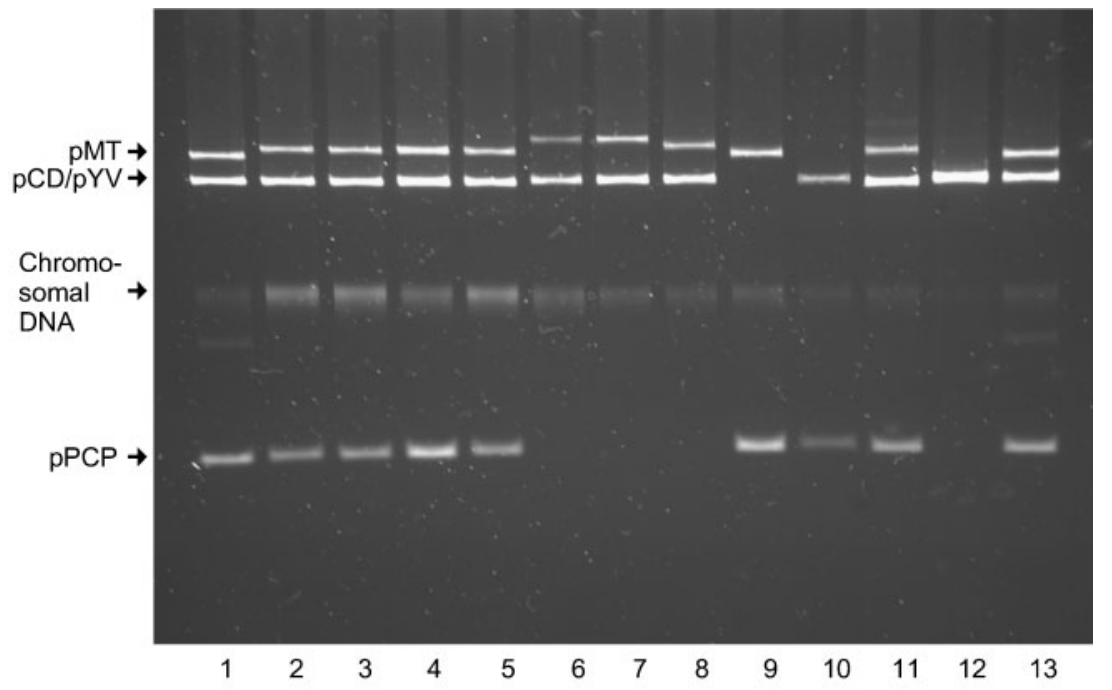

Fig. 1. Agarose gel illustrating the presence or absence of pPCP $(\sim 10 \mathrm{~kb}), \mathrm{pCD}$ or $\mathrm{pYV}$ $(\sim 70 \mathrm{~kb})$, and pMT $(\sim 100 \mathrm{~kb})$ in DNA purified from epidemic $Y$. pestis CO92 (lanes 1, 13); enzootic $Y$. pestis pestoides A (lane 2), B (lane 3), C (lane 4), D (lane 5), E (lane 6), F (lane 7), G (lane 8), I (lane 9), J (lane 10), and Angola (lane 11) and Y. pseudotuberculosis TX830489 (lane 12). 
Table 1. Source and characteristics of the strains of yersiniae used in this study

\begin{tabular}{|c|c|c|c|c|c|c|c|c|c|}
\hline \multirow[t]{2}{*}{ Strain } & \multirow[t]{2}{*}{ Species } & \multirow[t]{2}{*}{ Epidemiological habit ${ }^{\star}$} & \multicolumn{5}{|c|}{ Determinative property $\dagger$} & \multirow{2}{*}{$\begin{array}{c}\text { Geographical origin } \\
\text { or source }\end{array}$} & \multirow[t]{2}{*}{ Reference } \\
\hline & & & Pgm & LCR & Caf1 & MT & Pla $\ddagger$ & & \\
\hline 1 & pseudotuberculosis & Enteropathogenic & - & - & - & - & - & Sweden & Thal \& Knapp (1971) \\
\hline 7 & pseudotuberculosis & Enteropathogenic & - & - & - & - & - & Sweden & Thal \& Knapp (1971) \\
\hline A16 & pestis & Enzootic & - & + & + & + & + & Africa & Devignat (1954) \\
\hline Angola & pestis & Enzootic & + & + & - & + & + & Africa & Achtman et al. (2004) \\
\hline Camel & pestis & Epidemic & + & + & + & + & + & Saudi Arabia & Bin Saeed et al. (2005) \\
\hline CO92 & pestis & Epidemic & + & + & + & + & + & Colorado, USA & Parkhill et al. (2001) \\
\hline E705 & enterocolitica & Enteropathogenic & - & + & - & - & - & Canada & Schiemann et al. (1981) \\
\hline KIM & pestis & Epidemic & + & + & + & + & + & Kurdistan, Iran & Finegold et al. (1968) \\
\hline Kuma & pestis & Epidemic & + & - & + & + & + & Manchuria & Wu et al. (1936) \\
\hline PB1 & pseudotuberculosis & Enteropathogenic & - & + & - & - & - & England & $\begin{array}{l}\text { Burrows \& Bacon } \\
\text { (1960) }\end{array}$ \\
\hline Pestoides A & pestis & Enzootic & + & + & + & + & + & Russia (CDC\$) & Achtman et al. (2004) \\
\hline Pestoides B & pestis & Enzootic & + & + & + & + & + & Russia (CDC) & Achtman et al. (2004) \\
\hline Pestoides C & pestis & Enzootic & - & + & + & + & + & Russia (CDC) & Achtman et al. (2004) \\
\hline Pestoides D & pestis & Enzootic & + & + & + & + & + & Russia (CDC) & Achtman et al. (2004) \\
\hline Pestoides E & pestis & Enzootic & + & + & + & + & - & Russia (CDC) & Achtman et al. (2004) \\
\hline Pestoides F & pestis & Enzootic & + & + & + & + & - & Russia (CDC) & Achtman et al. (2004) \\
\hline Pestoides G & pestis & Enzootic & + & + & + & + & - & Russia (CDC) & Achtman et al. (2004) \\
\hline Pestoides I & pestis & Enzootic & + & - & + & + & + & Russia (CDC) & - \\
\hline Pestoides J & pestis & Epidemic & - & + & - & - & + & Unknown & Achtman et al. (2004) \\
\hline TX83-0489 & pseudotuberculosis & Enteropathogenic & - & + & - & - & - & $\mathrm{CDC}$ & - \\
\hline UG05-0454 & pestis & Epidemic & + & + & + & + & + & $\mathrm{CDC}$ & - \\
\hline WA & enterocolitica & Enteropathogenic & - & + & - & - & - & New York, USA & Carter \& Collins (1974) \\
\hline Winblad & enterocolitica & Enteropathogenic & - & - & - & - & - & Sweden & Winblad et al. (1966) \\
\hline
\end{tabular}

${ }^{\star}$ The enzootic habit was initially assigned to all pestoides strains according to Martinevskii (1969).

$\dagger$ Pgm, pigmentation; LCR, low calcium response; Caf1, capsular antigen fraction 1; MT, murine toxin; Pla, plasminogen activator; + , positive; -, negative.

$\$$ Pla was determined semiquantitatively (Brubaker \& Surgalla, 1962):,$-<100 \mathrm{U} ;+,>10000 \mathrm{U}$.

$\$ C D C$, from the stock culture collection of the CDC laboratory, Fort Collins, CO. 
incubation for $10 \mathrm{~min}$, were assayed for absorbance at $480 \mathrm{~nm}$ as described for determination of asparaginase (Yellin \& Wriston, 1966). The resulting values were then compared against a standard curve prepared immediately before each determination composed of known concentrations of $\mathrm{NH}_{4} \mathrm{Cl}$ in samples of $10 \mathrm{ml}$ containing the same concentrations of trichloroacetic acid and Nessler's reagent that were used to prepare samples for spectrophotometric analysis. In all cases, protein was determined by the Lowry method.

Pyrosequencing. PCR was performed using an iCycler real-time thermocycler (Bio-Rad). DNA templates consisted of $1 \mu$ boiled lysis preparations or QIAamp DNA mini-preparations (Qiagen) of pure cultures grown on blood agar plates. Reactions consisted of $10 \mu \mathrm{l}$ SYBR Green SuperMix (Bio-Rad), $5 \mathrm{mM} \mathrm{MgCl}_{2}$ and $10 \mathrm{pmol}$ primers. The reaction volume was adjusted to $20 \mu \mathrm{l}$ with sterile, nuclease-free sequencing buffer (Amresco). Primers (Table 2) were designed using the PSQ Assay Design program (Biotage) and synthesized by the Scientific Resources Program (CDC, Atlanta, GA). The reverse primer in each primer pair was biotinylated at its 5prime end to facilitate streptavidin-mediated recovery of templates for subsequent pyrosequencing (Table 2). Amplification reactions were undertaken at $95{ }^{\circ} \mathrm{C}$ for 3 min followed by 45 cycles at $95{ }^{\circ} \mathrm{C}$ for $15 \mathrm{~s}$ and $60{ }^{\circ} \mathrm{C}$ for $30 \mathrm{~s}$. PCR analysis and crossing threshold $\left(C_{\mathrm{t}}\right)$ value assignment was determined automatically by the iQ software (data not shown). Sequencing was performed on a PSQ96MA pyrosequencer (Biotage) according to the manufacturer's recommendations. Briefly, PCRs were adjusted to $40 \mu \mathrm{l}$ with sterile MilliQ water (Millipore); a $40 \mu \mathrm{l}$ slurry of streptavidin-coated Sepharose beads (Amersham Biosciences) in binding buffer (Biotage) was added to each sample. Reactions were mixed at 1400 r.p.m. for $10 \mathrm{~min}$ then bound to filter probes (Biotage) by vacuum aspiration. The probes were washed in $70 \%$ ethanol, $0.2 \mathrm{M} \mathrm{NaOH}$ and wash buffer (Biotage) consecutively for $5 \mathrm{~s}$ each. The reaction mixes were eluted into a 96well sequencing plate containing $40 \mu \mathrm{l}$ aliquots of annealing buffer (Biotage) and sequencing primer $(20 \mathrm{pmol})$. Sequencing reactions were heated at $80{ }^{\circ} \mathrm{C}$ for $2 \mathrm{~min}$, and then allowed to cool to room temperature. The nucleotide dispensation orders were: zwf472-TA-
GCGATCTCAGTATACGATCAGTAGC, e-zwf472-GCGATCTCACGTGATACGATCAGTGCGATATCAC, aspA436-CACAGTATGCTACACGTCGCATGCGTCTAGC, e-aspA436-ACGTATGCTACACTGTCGCA, aspA1087-TACAGTCGATGAGCGTGATGTCAGCATGTGAGTCTATC, and e-aspA1087-CATCGATCGTCACTGAGCTGACTGCTCGCAGCATAG. All reactions were run in triplicate and pyrograms were analysed using the PSQ software (Biotage).

\section{RESULTS}

\section{General properties}

Previously designated species, associated epidemiological habit, major virulence functions, geographical origin or source, and salient references of all yersiniae used in this study are shown in Table 1. This information, as well as plasmid profiles, biochemical determinations and enzyme analyses, was used to combine organisms of similar habit in subsequent tables. Evidence is provided below in this context to reassign the pestoides J strain to the group of epidemic isolates and to retain the pestoides I strain within the group of enzootic isolates even though it failed to ferment rhamnose or melibiose.

\section{Plasmid profiles}

The plasmid profiles of enzootic pestoides variants were compared by agarose gel electrophoresis with those of a control isolate of epidemic Y. pestis CO92 and enteropathogenic Y. pseudotuberculosis TX83-0489 (Fig. 1). pMT appeared slightly larger in the pestoides A, B, C, D and Angola isolates as compared to the CO92 control (110 kb) due, at least in strain Angola, to two integrated copies of

Table 2. Primers used for the amplification ( $-f$ and $-r)$ and pyrosequencing $(-s)$ of codons for amino acid position 155 of Zwf and amino acid positions 146 (1) and 363 (2) of AspA from yersiniae

\begin{tabular}{|c|c|c|c|}
\hline Gene target & Primer & Sequence $\left(5^{\prime}-3^{\prime}\right)$ & $\begin{array}{c}\text { Amplicon size } \\
\text { (bp) }\end{array}$ \\
\hline \multirow[t]{3}{*}{$z w f$} & $z w f-f$ & TGGGAGAAGCCGGGTTAAA & 105 \\
\hline & $z w f-r$ & Biotin-ACTCGGCTACCTGATCGTTAATT & \\
\hline & $z w f-s$ & CATTGGGAACCGATT & \\
\hline \multirow[t]{3}{*}{$\mathrm{e}-z w f$} & $e z w f-f$ & CGCGGGTGGTAATGGAAAAA & 86 \\
\hline & $e z w f-r$ & Biotin-CTCGTTGAAATATTCGGCAA & \\
\hline & $e z w f-s$ & CATTGGGGAAAGATTTA & \\
\hline \multirow[t]{3}{*}{$\operatorname{asp} A(1)$} & aspA1-f & CСТTAACССТAACGACCATCTG & 90 \\
\hline & aspA1-r & Biotin-AGGATGGAGGCGTAGACCG & \\
\hline & aspA1-s & CAAATGCCAGTCCAC & \\
\hline \multirow[t]{3}{*}{$\mathrm{e}-\operatorname{asp} A(1)$} & easpA1-f & ACCTAAACCCTAATGACCATCTGA & 72 \\
\hline & easpA1-r & Biotin-CAATGCGGAACCCAGTTG & \\
\hline & easpA1-s & AAATGCCAATCCACC & \\
\hline \multirow[t]{3}{*}{$\operatorname{asp} A(2)$} & aspA2-f & TTTTAAGGTGATCGGCAACG & 127 \\
\hline & aspA2-r & Biotin-CGCATTAGTCAGGATATGGATAGA & \\
\hline & aspA2-s & AAGCGGGTCAGCTTCAGT & \\
\hline \multirow[t]{3}{*}{$\mathrm{e}-\operatorname{asp} A(2)$} & easpA2-f & Biotin-TACTATGGCTGCCGAAGCAGG & 97 \\
\hline & easpA2-r & CGCATTTGTCAGGATGTGGAT & \\
\hline & easpA2-s & CCCAATCACTGGCTC & \\
\hline
\end{tabular}


pPCP (NCBI accession NC_010158). As shown by separate measurements, pMT was further increased in size to $134 \mathrm{~kb}$ (pestoides E), $126 \mathrm{~kb}$ (pestoides F), and $118 \mathrm{~kb}$ (pestoides $\mathrm{G})$. These three isolates entirely lacked pPCP whereas $\mathrm{pCD}$ and pMT were absent in the pestoides I and $\mathrm{J}$ isolates, respectively.

\section{Nutritional requirements}

A chemically defined solid medium containing the minimal nutritional requirements of epidemic $Y$. pestis was used to identify compounds necessary for growth of the pestoides isolates. Pestoides strains A, B, C, E and G required L-arginine (Table 3). L-Leucine was essential for growth of the pestoides A, B, C and D isolates and a need for other amino acids was occasionally observed; requirements for purines, pyrimidines, or vitamins were not detected.

\section{Expression of virulence factors}

None of the $\mathrm{Pgm}^{+}$pestoides strains that were available for study (Table 3) yielded $\mathrm{Pgm}^{-}$mutants at high frequency as occurs in epidemic isolates of $Y$. pestis (Brubaker, 1969). Isolates lacking given plasmids also failed to express attendant virulence factors (Table 3) or encode salient

Table 3. Comparison of determinative properties of $Y$. pestis, $Y$. pseudotuberculosis and $Y$. enterocolitica

+ , Positive; -, negative (where applicable).

\begin{tabular}{|c|c|c|c|c|c|c|c|c|c|c|}
\hline Strain & $\begin{array}{l}\text { Glycerol } \\
\text { fermenta- } \\
\text { tion }\end{array}$ & $\begin{array}{c}\text { Nitrate } \\
\text { reduction }\end{array}$ & $\begin{array}{c}\text { Biotype } \\
\text { or } \\
\text { serotype }^{*}\end{array}$ & $\begin{array}{l}\text { Rhamnose } \\
\text { fermenta- } \\
\text { tion }\end{array}$ & $\begin{array}{l}\text { Melibiose } \\
\text { fermenta- } \\
\quad \text { tion }\end{array}$ & Urease & $\begin{array}{l}\text { Motility } \\
\text { at } 26^{\circ} \mathrm{C}\end{array}$ & $\begin{array}{c}\text { Nutritional } \\
\text { require- } \\
\text { ments } \dagger\end{array}$ & $\begin{array}{c}\text { High-fre- } \\
\text { quency } \\
\Delta \text { Pgm } \ddagger\end{array}$ & $\begin{array}{l}\text { Sensitivity } \\
\text { to pesticin } \\
\left(\mathrm{U} \mathbf{~ m l}^{-1}\right) \S\end{array}$ \\
\hline Camel & + & - & Medievalis & - & - & - & - & None & + & 9 \\
\hline CO92 & - & + & Orientalis & - & - & - & - & None & + & 0 \\
\hline KIM-10 & + & - & Medievalis & - & - & - & - & None & + & 9 \\
\hline Pestoides J & - & - & (atypical) & - & - & - & - & None & NA & 0 \\
\hline UG05-0454 & + & + & Antiqua & - & - & - & - & None & + & 3 \\
\hline \multicolumn{11}{|c|}{ Enzootic $Y \cdot$ pestis } \\
\hline A16 & + & + & Antiqua & + & + & - & - & Pro & NA & 0 \\
\hline Angola & + & + & Antiqua & + & + & - & - & His & - & 27 \\
\hline Pestoides A & + & - & Medievalis & + & + & - & - & Arg, Leu & - & 27 \\
\hline Pestoides F & + & + & Antiqua & + & + & - & - & Tyr & - & 5877 \\
\hline Pestoides G & + & + & Antiqua & + & + & - & - & Pro, Arg & - & 1959 \\
\hline Pestoides I & + & + & Antiqua & - & - & - & - & None & - & 27 \\
\hline \multicolumn{11}{|c|}{$\begin{array}{l}\text { Enteropathogenic } \\
\text { Y. pseudotuber- } \\
\text { culosis }\end{array}$} \\
\hline 1 & + & + & $\mathrm{O}: \mathrm{Ia}$ & + & + & + & + & None & NA & 2187 \\
\hline PB1 & + & + & $\mathrm{O}: \mathrm{Ib}$ & + & + & + & + & None & NA & 2187 \\
\hline 7 & + & + & $\mathrm{O}: \mathrm{IIa}$ & + & + & + & + & None & NA & 0 \\
\hline TX83-0489 & + & + & $\mathrm{O}: \mathrm{Ib}$ & + & + & + & + & None & NA & 2187 \\
\hline \multicolumn{11}{|c|}{$\begin{array}{l}\text { Enteropathogenic } \\
\text { Y. enterocolitica }\end{array}$} \\
\hline
\end{tabular}

${ }^{*}$ Biotypes of $Y$. pestis as defined by Devignat (1951) and serotypes of Y. pseudotuberculosis and Y. enterocolitica according to Thal \& Knapp (1971) and Winblad (1968), respectively.

$\dagger$ Determined with added L-methionine, L-phenylalanine, L-cysteine and L-threonine typically required by cells of epidemic strains of Y. pestis (Brubaker \& Sulen, 1971); 'none' indicates growth on this medium without supplementation.

$\ddagger$ Capability of undergoing high-frequency $\left(10^{-5}\right)$ mutation to Pgm $^{-}$(Brubaker, 1969); NA, not applicable (due to the isolate already being Pgm ${ }^{-}$). §Reciprocal of the highest dilution exhibiting visible inhibition of growth on pesticin agar. 
genes detectable by PCR, emphasizing that these missing plasmids were indeed cured rather than integrated into the chromosome. Similarly, carriage of plasmids was associated with expression of known encoded virulence factors with the exception of the Angola isolate, which possessed pMT and produced MT (as detected by immunoassay) but not linked Caf1. In this context, it is significant that there were no matches against the completed Angola genome using caf1 from $Y$. pestis KIM as a query.

\section{Pesticin}

All pestoides strains harbouring pPCP produced similar amounts of the bacteriocin pesticin as judged by uniform zones of inhibition $(8-10 \mathrm{~mm})$ surrounding individual colonies overlayered with indicator cells of $Y$. pseudotuberculosis PB1. Isolates lacking pPCP (pestoides E, F and G) did not produce pesticin and were acutely sensitive to this bacteriocin as compared to pesticinogenic strains able to produce pPCP-encoded pesticin immunity protein (Table 3). Nevertheless, as reported by others (Anisimov et al.,
2004), a few pesticinogenic pestoides variants exhibited modest sensitivity to pesticin.

\section{Determinative properties}

All tested pestoides isolates as well as epidemic strains of $Y$. pestis failed to hydrolyse urea or exhibit motility at $26{ }^{\circ} \mathrm{C}$. In contrast, all of the pestoides strains except I resembled $Y$. pseudotuberculosis in that they fermented rhamnose and melibiose.

\section{Glucose-6-phosphate dehydrogenase}

Dialysed cell-free extracts of all tested epidemic $Y$. pestis controls lacked detectable Zwf activity as judged by direct enzymic assay whereas control extracts of enteropathogenic yersiniae were positive (Table 4). Only the pestoides E, F and $G$ strains exhibited detectable Zwf. As reported previously, the only known difference between the enzymically active enzyme in $Y$. pseudotuberculosis and the inactive form in epidemic $Y$. pestis is the presence of

Table 4. Codons for amino acids at position 155 of glucose-6-phosphate dehydrogenase (Zwf) and position 363 of aspartase (AspA) and corresponding specific activities in dialysed cell-free extracts prepared from yersiniae expressing these enzymes

\begin{tabular}{|c|c|c|c|c|c|c|}
\hline \multirow[t]{2}{*}{ Strain } & \multicolumn{3}{|c|}{ Glucose-6-phosphate dehydrogenase (Zwf) } & \multicolumn{3}{|c|}{ L-Aspartate ammonia-lyase or aspartase (AspA) } \\
\hline & Codon & Amino acid & Specific activity ${ }^{\star}$ & Codon & Amino acid & Specific activity ${ }^{\star}$ \\
\hline \multicolumn{7}{|c|}{ Epidemic $Y \cdot$ pestis } \\
\hline Camel & CCC & Pro & $\leqslant 0.001$ & UUG & Leu & $\leqslant 0.001$ \\
\hline CO92 & CCC & Pro & $\leqslant 0.001$ & UUG & Leu & $\leqslant 0.001$ \\
\hline KIM10 & CCC & Pro & $\leqslant 0.001$ & UUG & Leu & $\leqslant 0.001$ \\
\hline Kuma & CCC & Pro & $\leqslant 0.001$ & UUG & Leu & $\leqslant 0.001$ \\
\hline Pestoides J & CCC & Pro & $\leqslant 0.001$ & UUG & Leu & $\leqslant 0.001$ \\
\hline UG05-0454 & CCC & Pro & $\leqslant 0.001$ & UUG & Leu & $\leqslant 0.001$ \\
\hline \multicolumn{7}{|c|}{ Enzootic $Y$. pestis } \\
\hline A16 & CCC & Pro & $\leqslant 0.001$ & UUU & Phe & 0.020 \\
\hline Angola & CCC & Pro & $\leqslant 0.001$ & UUU & Phe & 0.008 \\
\hline Pestoides A & CCC & Pro & $\leqslant 0.001$ & GUG & Val & 0.064 \\
\hline Pestoides B & CCC & Pro & $\leqslant 0.001$ & GUG & Val & 0.042 \\
\hline Pestoides C & CCC & Pro & $\leqslant 0.001$ & GUG & Val & 0.057 \\
\hline Pestoides D & CCC & Pro & $\leqslant 0.001$ & GUG & Val & 0.028 \\
\hline Pestoides E & UCC & Ser & 0.093 & UCG & Ser & 0.052 \\
\hline Pestoides F & UCC & Ser & 0.084 & UCG & Ser & 0.039 \\
\hline Pestoides G & UCC & Ser & 0.089 & UCG & Ser & 0.050 \\
\hline Pestoides I & CCC & Pro & $\leqslant 0.001$ & UCG & Ser & 0.050 \\
\hline \multicolumn{7}{|c|}{ Y. pseudotuberculosis } \\
\hline 1 & UCC & Ser & 0.102 & GUG & Val & 0.172 \\
\hline PB1 & UCC & Ser & 0.083 & GUG & Val & 0.137 \\
\hline 7 & UCC & Ser & 0.101 & GUG & Val & 0.059 \\
\hline TX83-0489 & UCC & Ser & 0.080 & GUG & Val & 0.072 \\
\hline \multicolumn{7}{|c|}{ Y. enterocolitica } \\
\hline Winblad & UCC & Ser & 0.119 & GUC & Val & 0.202 \\
\hline WA & UCC & Ser & 0.104 & GUC & Val & 0.202 \\
\hline E705 & UCC & Ser & 0.097 & GUC & Val & 0.207 \\
\hline
\end{tabular}

${ }^{\star}$ Values are expressed as $\mu \mathrm{mol}$ product produced $\min ^{-1}(\mathrm{mg} \text { protein })^{-1}$ and are averaged from at least two independent determinations; variation was $<15 \%$. 
serine instead of proline at amino acid position 155 (Chain et al., 2004). Results obtained by pyrosequencing (Table 4) demonstrated that all active enzymes, including those of the pestoides $\mathrm{E}, \mathrm{F}$ and $\mathrm{G}$ isolates, contained serine (encoded by UCC) at position 155 whereas all inactive enzymes contained proline (encoded by CCC).

\section{Aspartase}

As expected, dialysed cell-free extracts of all tested epidemic $Y$. pestis controls lacked detectable AspA activity as shown by direct enzymic assay whereas extracts of all control enteropathogenic yersiniae were positive (Table 4). All of the enzootic variants of $Y$. pestis also expressed biologically functional AspA, although variation was observed in specific activity. The results of DNA sequencing verified that the codon for valine at amino acid position 363 of the active enzymes of $Y$. pseudotuberculosis was GUG and that this similarly encoded amino acid was present at the same position of the active enzymes from the pestoides $\mathrm{A}, \mathrm{B}, \mathrm{C}$ and $\mathrm{D}$ isolates. In contrast, position 363 of the enzymes from the pestoides E, F, G and I strains was occupied by serine (encoded by UCG) while that of the less active enzymes from the Angola and A16 isolates was phenylalanine (encoded by UUU). The distantly related $Y$. enterocolitica also contained valine at amino acid position 363 of fully active AspA but its codon was GUC.

AspA from strain Angola was purified to near homogeneity as described for AspA of Y. pseudotuberculosis and the corresponding CRIM (cross-reacting immunological material) of $Y$. pestis and subjected to similar kinetic analysis (Viola et al., 2008). The specific activity of the

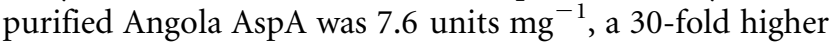
estimate than the nearly inactive $Y$. pestis CRIM but still more than 10-fold lower than the AspA of Y. pseudotuberculosis. The Angola enzyme had a comparable $K_{\mathrm{m}}$ of $4.4 \pm 1.2 \mathrm{mM}$ for L-aspartate but, similar to the $Y$. pestis CRIM, exhibited a reduced $k_{\text {cat }}\left(7.8 \pm 1.0 \mathrm{~s}^{-1}\right)$. As a consequence, the $k_{\mathrm{cat}} / K_{\mathrm{m}}$ of the Angola AspA was $1800 \pm 200 \mathrm{M}^{-1} \mathrm{~s}^{-1}$, a value of only $4.2 \%$ of the $Y$. pseudotuberculosis enzyme but still significantly more active than the $Y$. pestis CRIM (0.2\%) (Viola et al., 2008).

Amino acid position 146 of AspA consists of aspartic acid in Y. pseudotuberculosis (Chain et al., 2004) and Y. pestis strain CO92 (Parkhill et al., 2001) but is occupied by tyrosine in $Y$. pestis strain KIM (Deng et al., 2002). As judged by pyrosequencing, the codons of the aspartic acid and tyrosine residues at this location are GAU and UAU, respectively. Only the pestoides $J$ and epidemic Camel isolates resembled $Y$. pestis $\mathrm{KIM}$ in encoding tyrosine at amino acid position 146; all remaining yersiniae that were evaluated expressed aspartic acid at this location. These results are consistent with the hypothesis that the transversion $(\mathrm{G} \cdot \mathrm{C} \rightarrow \mathrm{T} \cdot \mathrm{A})$ at amino acid 146 of AspA occurs only in a limited (biovar medievalis) clone of Middle Eastern origin.

\section{DISCUSSION}

\section{The pestoides phenotype}

The pestoides collection used in this study comprised strains that likely possessed all virulence factors known to exist at the time of their isolation, but which nevertheless failed to cause disease in guinea pigs. It is well known that the $\mathrm{Lcr}^{+}$and $\mathrm{Pgm}^{+}$phenotypes of $Y$. pestis are lost at the high rates of $10^{-4}$ (Higuchi \& Smith, 1961) and $10^{-5}$ (Brubaker, 1969), respectively, and that Caf1 is also lost at high frequency (Burrows, 1957; Burrows \& Bacon, 1958). The possibility therefore exists that these determinants were initially present upon primary isolation but lost during subsequent storage. In this regard, $\mathrm{pCD}$ is absent in pestoides I, and pestoides J lacked pMT, which encodes MT and Caf1. Cells of the Angola strain carried pMT but failed to express detectable Caf1 as judged by immunoassay, real-time PCR and query versus cafl of Y. pestis KIM. Deficiency of Caf1 is sufficient to cause reduced virulence in guinea pigs (Burrows, 1957); these phenomena alone may have prompted inclusion of the Angola and pestoides $\mathrm{J}$ strains among the enzootic variants. The pestoides $\mathrm{E}, \mathrm{F}$ and $\mathrm{G}$ isolates lacked pPCP encoding plasminogen activator, a known invasive virulence factor of epidemic Y. pestis (Brubaker et al., 1965; Lähteenmäki et al., 1998; Sodeinde et al., 1992). However, this deficiency in the pestoides $\mathrm{F}$ isolate did not influence virulence in mice by peripheral routes of injection (Worsham \& Hunter, 1998; Worsham \& Roy, 2003) although the absence of plasminogen activator might account for attenuation in hosts other than Muridae. The pestoides E, F and G isolates also carried oversize pMT plasmids similar to a pestoides strain from the Caucasus (Golubov et al., 2004).

The mutation frequency to $\mathrm{Pgm}^{-}$provided another criterion that distinguished tested enzootic and epidemic isolates of $Y$. pestis. The high mutation rate to pesticin resistance in epidemic $\mathrm{Pgm}^{+}$yersiniae lacking pPCP (Brubaker, 1969) reflects the fact that the $\sim 100 \mathrm{~kb}$ deletable Pgm region (Lucier \& Brubaker, 1992) is flanked by polar IS elements that undergo reciprocal recombination, thereby favouring deletion of the entire sequence (Fetherston et al., 1992; Fetherston \& Perry, 1994). This event eliminates the $\mathrm{Hms}^{+}$locus responsible for pigment binding and biofilm production (Kirillina et al., 2004; Perry et al., 2001), the yersiniabactin operon including the pesticin/yersiniabactin receptor (Fetherston et al., 1995), and rip $A B C$ required for growth in macrophages activated post-infection (Pujol et al., 2005). Yersiniae that undergo this high-frequency deletion therefore lose the linked pesticin receptor (Fetherston et al., 1992; Fetherston \& Perry, 1994) and are thus resistant to pesticin. Similarly, yersiniae and other enterobacteriaceae that otherwise lack this receptor typically exhibit little or no sensitivity to pesticin (Buchrieser et al., 1999). Typical pestoides isolates, however, were found by Zudina (2000) to possess only one flanking IS element and are therefore incapable of yielding Pgm isolates at high frequency. Mutation to Pgm in our 
pestoides strains also occurred at low frequency and this event was ostensibly a point mutation as judged by retention of other elements of the Pgm locus.

Results of further study showed that some of the pestoides isolates possessed nutritional requirements not shared by typical epidemic strains of $Y$. pestis. Further effort will be required to determine the missing enzymes accounting for these requirements but it may be significant that certain arginine auxotrophs of $Y$. pestis are known to be attenuated in guinea pigs but not mice (Brubaker, 1972). Most isolates considered here were typical of those described in the literature in that they fermented rhamnose and melibiose but lacked other obvious properties of $Y$. pseudotuberculosis. A major exception to this rule was the pestoides I isolate, which did not ferment either one of these carbohydrates. Considered together, our characterization of this collection as it presently exists is generally consistent with previous reports of enzootic variants (Achtman et al., 2004; Anisimov et al., 2004; Garcia et al., 2007; Golubov et al., 2004) and supports consideration of the pestoides A, B and $\mathrm{C}$ isolates as $Y$. pestis subspecies altaici, D as hissarica, and E, F and G as caucasia (Anisimov et al., 2004).

The pestoides $\mathrm{J}$ isolate was an authentic epidemic isolate as judged by typical loss of $z w f$ and aspA. This strain was also atypical in that it is negative for both glycerol fermentation and nitrate reduction and therefore does not correspond to any of Devignat's biovars (Devignat, 1951). However, like the Middle Eastern epidemic KIM and Camel strains (biovar medievalis), pestoides J encodes a tyrosine residue rather than aspartic acid at amino acid position 146 of AspA, suggesting the same clonal origin.

\section{The Zwf determinant}

The pestoides $\mathrm{E}, \mathrm{F}$ and $\mathrm{G}$ strains contained serine at amino acid position 155 of Zwf and thus expressed full biological activity. These isolates are therefore more closely related to their progenitor ( $Y$. pseudotuberculosis) than are the remaining pestoides strains which, like epidemic $Y$. pestis, contained inactive proline at this location. The position of these three strains in the initial phase of the evolutionary pathway leading to epidemic Y. pestis is also supported by the absence of pPCP and carriage of atypically large and probably more primitive pMT (Golubov et al., 2004).

$\mathrm{Zwf}^{-}$mutants of Escherichia coli exhibit a silent phenotype that requires concomitant loss of transketolase or transaldolase in the absence of pentose before growth becomes limited (Fraenkel, 1968). Transketolase and transaldolase are functional in both $Y$. pseudotuberculosis (Brubaker, 1968) and Y. pestis (Mortlock, 1962); furthermore, exogenous pentose is probably always available to $Y$. pestis during its closed life cycle. In this context, catabolism of gluconate, arabinose and ribose undergoes significant upregulation at $37^{\circ} \mathrm{C}$ in cells of the epidemic strain KIM (Motin et al., 2004), further emphasizing the dispensable nature of biosynthetic Zwf. On the other hand, Zwf is a major supplier of NADPH to the bacterial cell and a deficiency of this intermediate could have serious consequences during expression of the LCR. It would therefore be interesting to determine if cells of the $\mathrm{Zwf}^{+}$pestoides isolates are resistant to the D-glucose-dependent lysis in synthetic medium reported for epidemic strains of $Y$. pestis (Brownlow \& Wessman, 1960). These findings emphasize that loss of Zwf is an obvious early milestone in the emergence of $Y$. pestis from Y. pseudotuberculosis.

\section{The AspA determinant}

It is remarkable that all of the tested pestoides isolates expressed at least partially active AspA. This phenomenon resulted from either retention of valine at amino acid number 363 (pestoides A, B, C and D) or intragenic suppressor mutations causing introduction at that position of serine (pestoides E, F, G and I) or phenylalanine (Angola and A16). The specific activity of crude AspA from strain Angola was unusually low, due perhaps to the presence of a second missense mutation in this enzyme at amino acid position 378 causing replacement of isoleucine with threonine (NCBI accession no. NC_010159.1). Further study will be necessary to determine if the marginal activity of AspA in strain Angola reflects this additional amino acid substitution. In any event, the reduced activity detected for the crude extract of the Angola enzyme remained proportional to that observed for the purified cloned enzyme. The basis of this decrease, as in the case of the essentially inert AspA of $Y$. pestis caused by replacement of leucine for valine at position 363 (Viola et al., 2008), was a markedly reduced $k_{\text {cat }}$ but little change in the $K_{\mathrm{m}}$ for aspartic acid. This finding is in accord with the previous suggestion that mutations at position 363 indirectly inhibit enzyme activity by altering the position of catalytic residues Glu334 and Gln191, thereby disrupting their contributions to turnover (Viola et al., 2008).

Elimination of AspA, unlike Zwf, may have untoward consequences for the host. As already noted, this mutation accentuates the $\mathrm{pCD} / \mathrm{pYV}$-dependent nutritional requirement for $\mathrm{Ca}^{2+}$ at $37{ }^{\circ} \mathrm{C}$ and promotes excretion of $\mathrm{L}-$ aspartic acid at the expense of metabolic L-glutamate (Brubaker, 2005; Dreyfus \& Brubaker, 1978). This event, should it occur in vivo, could be deleterious by altering the equilibrium of amino acid pools, thereby reducing host adenylate energy charge. It is significant that the aspA of the attenuated microtus biovar encodes valine at amino acid position 363, indicating that AspA is active in these organisms; cells of this enzootic isolate are also attenuated in man (Fan et al., 1995) but are fully virulent in mice (Zhou et al., 2004). AspA is widespread among saprophytic bacteria but was neither required for virulence of salmonellae (Tchawa Yimga et al., 2006) nor detected in the genomes of other facultative intracellular parasites including Mycobacterium tuberculosis (Fleischmann et al., 2002) and Francisella tularensis (Larsson et al., 2005) or obligate intracellular rickettsiae (Andersson et al., 1998). 
The latter, like epidemic isolates of $Y$. pestis, also convert exogenous L-glutamate to L-aspartate, which is released into the culture medium (Bovarnick \& Miller, 1950).

Some of the enzootic strains used in this study possessed mutations that would cause attenuation of even epidemic isolates in guinea pigs. Formal proof demonstrating that mutational loss of AspA activity in epidemic isolates of $Y$. pestis and the consequences of this loss are directly associated with lethality in guinea pigs (and humans) will require additional effort involving exchange of asp A. The present study, however, provides convincing evidence that functional AspA is at least a biomarker for attenuation.

\section{ACKNOWLEDGEMENTS}

This work was sponsored by the NIH/NIAID Regional Center of Excellence for Bio-defense and Emerging Infectious Diseases Research (RCE) Program. R. R. B. wishes to acknowledge membership within and support from the Region V 'Great Lakes' RCE (NIH award 1U54-AI-057153).

\section{REFERENCES}

Abramov, V. M., Khlebnikov, V. S., Vasiliev, A. M., Kosarev, I. V., Vasilenko, R. N., Kulikova, N. L., Khodyakova, A. V., Evstigneev, V. I., Uversky, V. N. \& other authors (2007). Attachment of LcrV from Yersinia pestis at dual binding sites to human TLR-2 and human IFN$\gamma$ receptor. J Proteome Res 6, 2222-2231.

Achtman, M., Zurth, K., Morelli, G., Torrea, G., Guiyoule, A. \& Carniel, E. (1999). Yersinia pestis, the cause of plague, is a recently emerged clone of Yersinia pseudotuberculosis. Proc Natl Acad Sci U S A 96, 14043-14048.

Achtman, M., Morelli, G., Zhu, P., Wirth, T., Diehl, I., Kusecek, B., Vogler, A. J., Wagner, D. M., Allender, C. J. \& other authors (2004). Microevolution and history of the plague bacillus, Yersinia pestis. Proc Natl Acad Sci U S A 101, 17837-17842.

Andersson, S. G., Zomorodipour, A., Andersson, J. O., SicheritzPontén, T., Alsmark, U. C., Podowski, R. M., Näslund, A. K., Eriksson, A. S., Winkler, H. H. \& Kurland, C. G. (1998). The genome sequence of Rickettsia prowazekii and the origin of mitochondria. Nature 396, 133-140.

Anisimov, A. P., Lindler, L. E. \& Pier, G. B. (2004). Intraspecific diversity of Yersinia pestis. Clin Microbiol Rev 17, 434-464.

Anisimov, A. P., Panfertsev, E. A., Svetoch, T. E. \& Dentovskaya, S. V. (2007). Variability of the protein sequences of LcrV between epidemic and atypical rhamnose-positive strains of Yersinia pestis. Adv Exp Med Biol 603, 23-27.

Astrup, T. \& Mullertz, S. (1952). The fibrin plate method for estimating fibrinolytic activity. Arch Biochem Biophys 40, 346-351.

Beesley, E. D., Brubaker, R. R., Janssen, W. A. \& Surgalla, M. J. (1967). Pesticins. III. Expression of coagulase and mechanism of fibrinolysis. J Bacteriol 94, 19-26.

Bin Saeed, A. A., Al-Hamdan, N. A. \& Fontaine, R. E. (2005). Plague from eating raw camel liver. Emerg Infect Dis 11, 1456-1457.

Bovarnick, M. R. \& Miller, J. C. (1950). Oxidation and transamination of glutamate by typhus rickettsiae. J Biol Chem 184, 661-676.

Brownlow, W. J. \& Wessman, G. E. (1960). Nutrition of Pasteurella pestis in chemically defined media at temperatures of 36 to $38 \mathrm{C}$. J Bacteriol 79, 299-304.
Brubaker, R. R. (1968). Metabolism of carbohydrates by Pasteurella pseudotuberculosis. J Bacteriol 95, 1698-1705.

Brubaker, R. R. (1969). Mutation rate to nonpigmentation in Pasteurella pestis. J Bacteriol 98, 1404-1406.

Brubaker, R. R. (1972). Yersinia: biochemistry and genetics of virulence. Curr Top Microbiol Immunol 57, 111-158.

Brubaker, R. R. (1991). Factors promoting acute and chronic diseases caused by yersiniae. Clin Microbiol Rev 4, 309-324.

Brubaker, R. R. (2004). The recent emergence of plague: a process of felonious evolution. Microb Ecol 47, 293-299.

Brubaker, R. R. (2005). Influence of $\mathrm{Na}^{+}$, dicarboxylic amino acids, and $\mathrm{pH}$ in modulating the low-calcium response of Yersinia pestis. Infect Immun 73, 4743-4752.

Brubaker, R. R. (2007). Intermediary metabolism, $\mathrm{Na}^{+}$, the low calcium-response, and acute disease. In The Genus Yersinia: From Genomics to Function, pp. 116-129. Edited by R. D. Perry. New York: Springer.

Brubaker, R. R. \& Sulen, A. J. (1971). Mutations influencing the assimilation of nitrogen by Yersinia pestis. Infect Immun 3, 580-588.

Brubaker, R. R. \& Surgalla, M. J. (1962). Pesticins II. Production of pesticin I and II. J Bacteriol 84, 539-545.

Brubaker, R. R., Beesley, E. D. \& Surgalla, M. J. (1965). Pasteurella pestis: role of pesticin I and iron in experimental plague. Science 149, $422-424$.

Buchrieser, C., Rusniok, C., Frangeul, L., Couve, E., Billault, A., Kunst, F., Carniel, E. \& Glaser, P. (1999). The 102-kilobase pgm locus of Yersinia pestis: sequence analysis and comparison of selected regions among different Yersinia pestis and Yersinia pseudotuberculosis strains. Infect Immun 67, 4851-4861.

Burrows, T. W. (1957). Virulence of Pasteurella pestis. Nature 179, 1246-1247.

Burrows, T. W. \& Bacon, G. A. (1958). The effects of loss of different virulence determinants on the virulence and immunogenicity of strains of Pasteurella pestis. Br J Exp Pathol 39, 278-291.

Burrows, T. W. \& Bacon, G. W. (1960). V and W antigens in strains of Pasteurella pseudotuberculosis. Br J Exp Pathol 41, 38-44.

Carter, P. B. \& Collins, F. M. (1974). Experimental Yersinia enterocolitica infection in mice: kinetics of growth. Infect Immun $\mathbf{9}$, 851-857.

Chain, P. S., Carniel, E., Larimer, F. W., Lamerdin, J., Stoutland, P. O., Regala, W. M., Georgescu, A. M., Vergez, L. M., Land, M. L. \& other authors (2004). Insights into the evolution of Yersinia pestis through whole-genome comparison with Yersinia pseudotuberculosis. Proc Natl Acad Sci U S A 101, 13826-13831.

Chain, P. S. G., Hu, P., Malfatti, S. A., Radnedge, L., Larimer, F., Vergez, L. M., Worsham, P., Chu, M. C. \& Andersen, G. L. (2006). Complete genome sequence of Yersinia pestis strains Antiqua and Nepal516: evidence of gene reduction in an emerging pathogen. $J$ Bacteriol 188, 4453-4463.

Davies, D. A. L. (1961). Dideoxysugars of Pasteurella pseudotuberculosis-specific polysaccharides, and the occurrence of ascarylose. Nature 191, 43-44.

Deguchi, Y., Yamato, I. \& Anraku, U. (1990). Nucleotide sequence of gltS, the $\mathrm{Na}^{+}$/glutamate symport carrier gene of Escherichia coli. J Biol Chem 265, 21704-21708.

Deng, W., Burland, V., Plunkett, G. I., 3rd, Boutin, A., Mayhew, G. F., Liss, P., Perna, N. T., Rose, D. J., Mau, B. \& other authors (2002). Genome sequence of Y. pestis KIM. J Bacteriol 184, 4601-4611.

Devignat, R. (1951). Variétés de l'espèce Pasteurella pestis. Nouvelle hypothèse. Bull World Health Organ 4, 247-263. 
Devignat, R. (1954). Comportement biologique et biochimique de $P$. pestis et de P. pseudotuberculosis. Bull World Health Organ 10, 463494.

Dreyfus, L. A. \& Brubaker, R. R. (1978). Consequences of aspartase deficiency in Yersinia pestis. J Bacteriol 136, 757-764.

Fan, Z., Luo, Y., Wang, S., Jin, L., Zhou, X., Liu, J., Zhang, Y. \& Li, F. (1995). Microtus brandti plague in the Xilin Gol Grassland was inoffensive to humans. Chin J Control Endemic Dis 10, 56-57 (in Chinese).

Ferber, D. M. \& Brubaker, R. R. (1981). Plasmids in Yersinia pestis. Infect Immun 31, 839-841.

Fetherston, J. D. \& Perry, R. D. (1994). The pigmentation locus of Yersinia pestis $\mathrm{KIM6}^{+}$is flanked by an insertion sequence and includes the structural genes for pesticin sensitivity and HMWP2. Mol Microbiol 13, 697-708.

Fetherston, J. D., Schuetze, P. \& Perry, R. D. (1992). Loss of the pigmentation phenotype in Yersinia pestis is due to the spontaneous deletion of $102 \mathrm{~kb}$ of chromosomal DNA which is flanked by a repetitive element. Mol Microbiol 6, 2693-2704.

Fetherston, J. D., Lillard, J. W., Jr \& Perry, R. D. (1995). Analysis of the pesticin receptor from Yersinia pestis: role in iron deficient growth and possible regulation by its siderophore. J Bacteriol 177, 1824-1833.

Finegold, M. J., Petery, R. F., Berendt, R. F. \& Adams, H. R. (1968). Studies on the pathogenesis of plague. Blood coagulation and tissue responses of Macaca mulatta following exposure to aerosols of Pasteurella pestis. Am J Pathol 53, 99-114.

Fleischmann, R. D., Alland, D., Eisen, J. A., Carpenter, L., White, O., Peterson, J., DeBoy, R., Dodson, R., Gwinn, M. \& other authors (2002). Whole-genome comparison of Mycobacterium tuberculosis clinical and laboratory strains. J Bacteriol 184, 5479-5490.

Fowler, J. M. \& Brubaker, R. R. (1994). Physiological basis of the low calcium response in Yersinia pestis. Infect Immun 62, 5234-5241.

Fraenkel, D. G. (1968). Selection of Escherichia coli mutants lacking glucose-6-phosphate dehydrogenase or gluconate-6-phosphate dehydrogenase. J Bacteriol 95, 1267-1271.

Garcia, E., Nedialkov, Y. A., Elliott, J., Motin, V. L. \& Brubaker, R. R. (1999). Molecular characterization of KatY (antigen 5), a thermoregulated chromosomally encoded catalase-peroxidase of Yersinia pestis. J Bacteriol 181, 3114-3122.

Garcia, E., Worsham, P., Bearden, S., Malfatti, S., Lang, D., Larimer, F., Lindler, L. \& Chain, P. (2007). Pestoides F, an atypical Yersinia pestis strain from the former Soviet Union. Adv Exp Med Biol 603, 17-22.

Golubov, A., Neubauer, H., Nölting, C., Heesemann, J. \& Rakin, A. (2004). Structural organization of the pFra virulence-associated plasmid of rhamnose-positive Yersinia pestis. Infect Immun 72, 5613-5621.

Heesemann, J., Sing, A. \& Trülzsch, K. (2006). Yersinia's stratagem: targeting innate and adaptive immune defense. Curr Opin Microbiol $\mathbf{9}$, 55-61.

Higuchi, K. \& Smith, J. L. (1961). Studies on the nutrition and physiology of Pasteurella pestis. VI. A differential plating medium for the estimation of the mutation rate to avirulence. J Bacteriol 81, 605608.

Hinnebusch, B. J., Rudolph, A. E., Cherepanov, P., Dixon, J. D., Schwan, T. G. \& Forsberg, A. (2002). Role of Yersinia murine toxin in survival of Yersinia pestis in the midgut of the flea vector. Science 296, 733-735.

Hu, P. C. \& Brubaker, R. R. (1974). Characterization of pesticin: separation of antibacterial activities. J Biol Chem 249, 4749-4753.
Kado, C. I. \& Liu, S. T. (1981). Rapid procedure for detection of and isolation of large and small plasmids. J Bacteriol 145, 1365-1373.

Kirillina, O., Fetherston, J. D., Bobrov, A. G., Abney, J. \& Perry, R. D. (2004). HmsP, a putative phosphodiesterase, and HmsT, a putative diguanylate cyclase, control Hms-dependent biofilm formation in Yersinia pestis. Mol Microbiol 54, 75-88.

Kupferberg, L. L. \& Higuchi, K. (1958). Role of calcium ions in the stimulation of growth of virulent strains of Pasteurella pestis. J Bacteriol 76, 120-121.

Kutyrev, V. V., Popov, Y. A. \& Protsenko, O. A. (1986). Pathogenicity plasmids of the plague microbe (Yersinia pestis). Mol Gen Mikrobiol Virusol 6, 3-11.

Lähteenmäki, K., Virkola, R., Sarén, A., Emödy, E. \& Korhonen, T. K. (1998). Expression of the plasminogen activator Pla of Yersinia pestis enhances bacterial attachment to the mammalian extracellular matrix. Infect Immun 66, 5755-5762.

Larsson, P., Oyston, P. C., Chain, P., Chu, M. C., Duffield, M., Fuxelius, H. H., Garcia, E., Hälltorp, G., Johansson, D. \& other authors (2005). The complete genome sequence of Francisella tularensis, the causative agent of tularemia. Nat Genet 37, 153-159.

Lowry, O. H., Rosebrough, N. J., Farr, A. L. \& Randall, R. J. (1951). Protein measurement with the Folin phenol reagent. J Biol Chem 193, 265-275.

Lucier, T. S. \& Brubaker, R. R. (1992). Determination of genome size, macrorestriction pattern polymorphism, and nonpigmentation-specific deletion in Yersinia pestis by pulsed-field gel electrophoresis. J Bacteriol 174, 2078-2086.

Martinevskii, I. L. (1969). Biology and Genetic Features of Plague and Plague-Related Microbes. Moscow, USSR: Meditsina Press.

Mortlock, R. P. (1962). Gluconate metabolism of Pasteurella pestis. J Bacteriol 84, 53-59.

Mortlock, R. P. \& Brubaker, R. R. (1962). Glucose-6-phosphate dehydrogenase and 6-phosphogluconate dehydrogenase activities of Pasteurella pestis and Pasteurella pseudotuberculosis. J Bacteriol 84, 1122-1123.

Motin, V. L., Georgescu, A. M., Fitch, J. P., Gu, P. P., Nelson, D. O., Mabery, S. L., Garnham, J. B., Sokhansanj, B. A., Ott, L. L. \& other authors (2004). Temporal global changes in gene expression during temperature transition in Yersinia pestis. J Bacteriol 186, 6298-6305.

Parkhill, J., Wren, B. W., Thomson, N. R., Titball, R. W., Holden, M. T., Prentice, M. B., Sebaihia, M., James, K. D., Churcher, C. \& other authors (2001). Genome sequence of Yersinia pestis, the causative agent of plague. Nature 413, 523-527.

Perry, R. D., Bearden, S. W. \& Fetherston, J. D. (2001). Iron and heme acquisition and storage systems of Yersinia pestis. Recent Res Dev Microbiol 5, 13-27.

Protsenko, O. A., Anisimov, P. I., Mosarov, O. T., Donnov, N. P., Popov, Y. A. \& Kokushkin, A. M. (1983). Detection and characterization of Yersinia pestis plasmids determining pesticin I, fraction 1 antigen and mouse toxin synthesis. Genetika 19, 1081-1090.

Pujol, C., Grabenstein, J. P., Perry, R. D. \& Bliska, J. B. (2005). Replication of Yersinia pestis in interferon gamma-activated macrophages requires ripA, a gene encoded in the pigmentation locus. Proc Natl Acad Sci U S A 102, 12909-12914.

Schiemann, D. A., Devenish, J. A. \& Toma, S. (1981). Characteristics of virulence in human isolates of Yersinia enterocolitica. Infect Immun 32, 400-403.

Sodeinde, O. A., Subrahmanyam, Y. V. B. K., Stark, K., Quan, T., Bao, Y. \& Goguen, J. D. (1992). A surface protease and the invasive character of plague. Science 258, 1004-1007. 
Sun, Y. C., Hinnebusch, B. J. \& Darby, C. (2008). Experimental evidence for negative selection in the evolution of a Yersinia pestis pseudogene. Proc Natl Acad Sci U S A 105, 8097-8101.

Suntsov, V. \& Suntsova, N. (2008). Concepts of macro- and microevolution as related to the problem of origin and global expansion of the plague pathogen Yersinia pestis. Biol Bull 35, 333 338.

Surgalla, M. J. \& Beesley, E. D. (1969). Congo red-agar plating medium for detecting pigmentation in Pasteurella pestis. Appl Microbiol 18, 834-837.

Tchawa Yimga, M., Leatham, M. P., Allen, J. H., Laux, D. C., Conway, T. \& Cohen, P. S. (2006). Role of gluconeogenesis and the tricarboxylic acid cycle in the virulence of Salmonella enterica serovar Typhimurium in BALB/c mice. Infect Immun 74, 1130-1140.

Thal, E. \& Knapp, W. (1971). A revised antigenic scheme of Yersinia pseudotuberculosis. Symp Series Immunobiol Stand 15, 219-222.

Viola, R. E., Yerman, L., Fowler, J. M., Arvidson, C. G. \& Brubaker, R. R. (2008). A missense mutation causes aspartase-deficiency in Yersinia pestis. Microbiology 154, 1271-1280.

Winblad, S. (1968). Studies on O-antigen factors of "Yersinia enterocolitica". Prog Immunobiol Stand 9, 337-342.
Winblad, S., Nilehn, B. \& Jonsson, M. (1966). Two further cases, bacteriologically verified, of human infection with "Pasteurella X" (syn. Yersinia enterocolitica). Acta Pathol Microbiol Scand 67, 537-541.

Worsham, P. \& Hunter, M. (1998). Characterization of pestoides F, an atypical strain of $Y$. pestis. Medische Microbiologie 6, S34-S35.

Worsham, P. L. \& Roy, C. (2003). Pestoides F, a Yersinia pestis strain lacking plasminogen activator, is virulent by the aerosol route. $A d v$ Exp Med Biol 529, 129-131.

Wu, L.-T., Chun, J. W. H. \& Pollitzer, R. \& Wu, C. Y. (1936). Plague: a Manual for Medical and Public Health Workers. Shanghai: China.

Yellin, T. O. \& Wriston, J. C. (1966). Purification and properties of guinea pig serum asparaginase. Biochemistry 5, 1605.

Zhou, D., Tong, Z., Song, Y., Han, Y., Pei, D., Pang, X., Zhai, J., Li, M., Cui, B. \& other authors (2004). Genetics of metabolic variations between Yersinia pestis biovars and the proposal of a new biovar, microtus. J Bacteriol 186, 5147-5152.

Zudina, I. V. (2000). Genetic characterization of the chromosomal pigmentation region of five Yersinia pestis subspecies. $\mathrm{PhD}$ dissertation, Russian Research Anti-Plague Institute 'Microbe', Saratov, Russia.

Edited by: P. van der Ley 